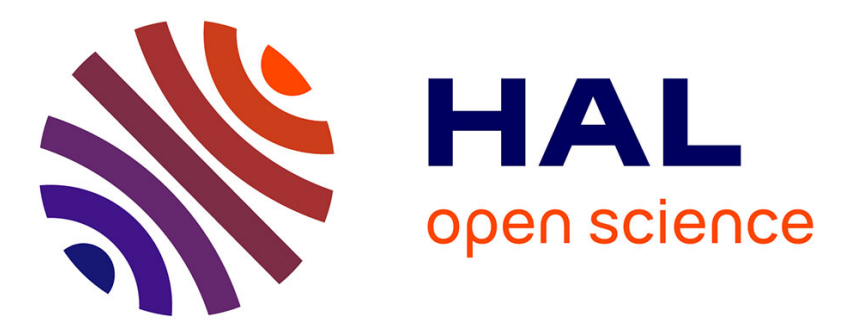

\title{
Self-assembly of colloidal polymers from two-patch silica nanoparticles
}

\author{
Weiya Li, Bin Liu, Céline Hubert, Adeline Perro, Etienne Duguet, Serge \\ Ravaine
}

\section{- To cite this version:}

Weiya Li, Bin Liu, Céline Hubert, Adeline Perro, Etienne Duguet, et al.. Self-assembly of colloidal polymers from two-patch silica nanoparticles. Nano Research, 2020, 13 (12), pp.3371-3376. 10.1007/s12274-020-3024-1 . hal-02968505

\section{HAL Id: hal-02968505 \\ https://hal.science/hal-02968505}

Submitted on 15 Oct 2020

HAL is a multi-disciplinary open access archive for the deposit and dissemination of scientific research documents, whether they are published or not. The documents may come from teaching and research institutions in France or abroad, or from public or private research centers.
L'archive ouverte pluridisciplinaire $\mathbf{H A L}$, est destinée au dépôt et à la diffusion de documents scientifiques de niveau recherche, publiés ou non, émanant des établissements d'enseignement et de recherche français ou étrangers, des laboratoires publics ou privés. 


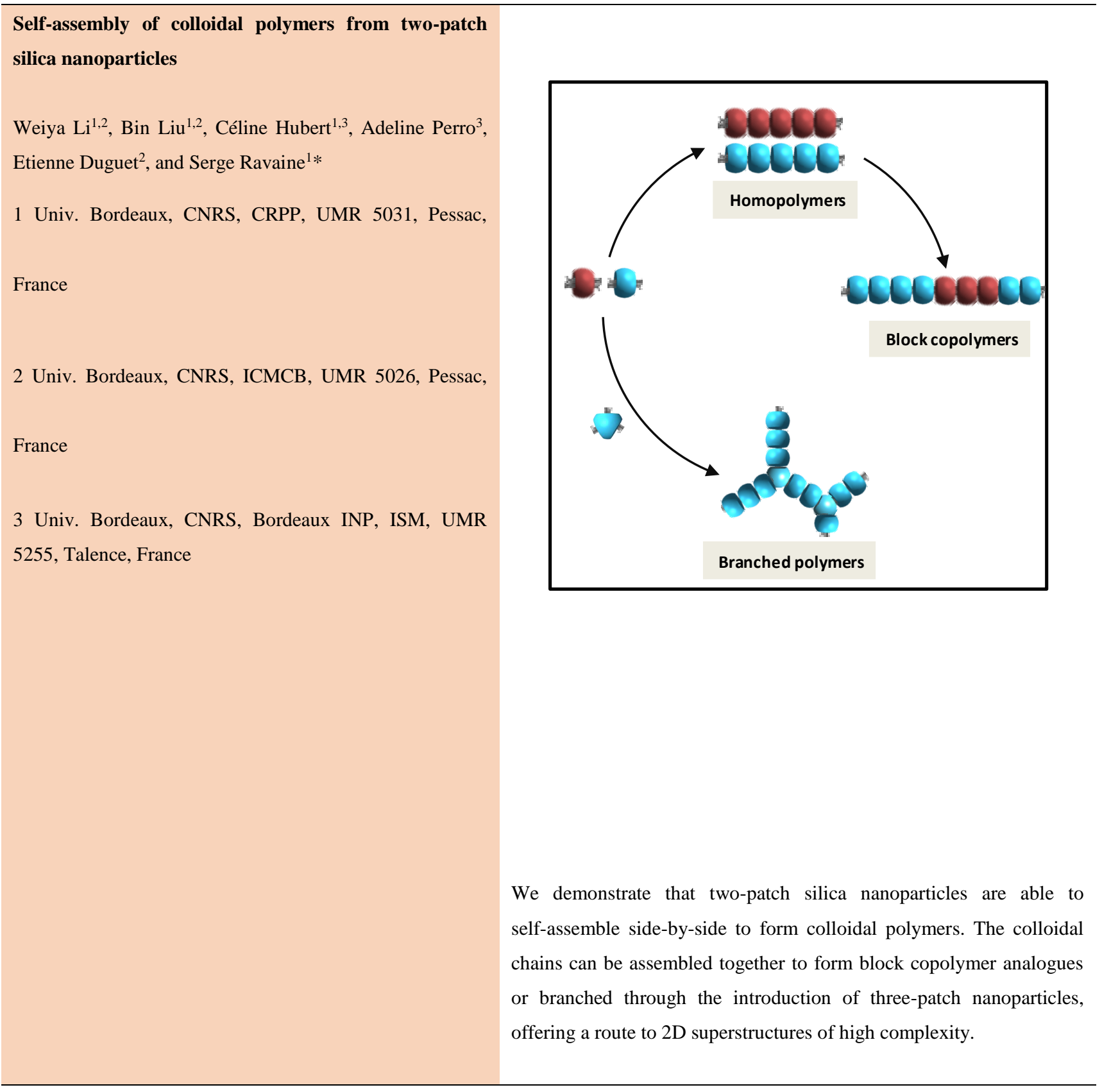





\title{
Self-assembly of colloidal polymers from two-patch silica nanoparticles
}

\author{
Weiya Li ${ }^{1,2}$, Bin Liu ${ }^{1,2}$, Céline Hubert ${ }^{1,3}$, Adeline Perro ${ }^{3}$, Etienne Duguet ${ }^{2}$, and Serge Ravaine ${ }^{1}(\square)$ \\ ${ }^{1}$ Univ. Bordeaux, CNRS, CRPP, UMR 5031, F-33600 Pessac, France \\ ${ }^{2}$ Univ. Bordeaux, CNRS, ICMCB, UMR 5026, F-33600 Pessac, France \\ ${ }^{3}$ Univ. Bordeaux, CNRS, Bordeaux INP, ISM, UMR 5255, F-33400 Talence, France
}

\author{
Received: day month year \\ Revised: day month year \\ Accepted: day month year \\ (automatically inserted by \\ the publisher) \\ (C) Tsinghua University Press \\ and Springer-Verlag Berlin \\ Heidelberg 2014

\section{KEYWORDS}

$\begin{array}{lr}\text { colloidal } & \text { polymers, } \\ \text { nanoparticles, } & \text { patchy, } \\ \text { self-assembly } & \end{array}$

\begin{abstract}
We report the formation of colloidal polymers consisting of disk-like silica nanoparticles (NPs) with polystyrene (PS) chains at the bottom of their two cavities assembled through reduction of the solvent quality for the PS chains and linked by hydrophobic associations. We show that this NPs assembly exhibits a two-stage process involving reaction-controlled polymerization and diffusion-controlled polymerization. Colloidal polymer networks are produced by the incorporation of three-patch NPs, which serve as branching points between the colloidal chains. By co-assembling preformed homopolymers composed of patchy NPs of different sizes or surface chemical groups, block copolymers are also achieved. This study provides insight into the process of self-assembly of two-patch NPs by precisely designing the components to generate colloidal analogues of linear macromolecular chains.
\end{abstract}

\section{Introduction}

There are numerous examples of complex structures that result from spontaneous chemical and/or physical processes with no external guidance [1], three-dimensional structures obtained through proteins folding being one of the most striking. Such a synthetic pathway requires that the instructions that guide the formation of a target structure are distributed among the building blocks, unlike top-down strategies for which the information is stored in a centralized location. A popular way to encode assembly information in colloidal components consists in the regioselective modification of their surface in order to form the so-called patchy particles [2]. A patchy particle is a surface-patterned particle with a controlled number of precisely located chemical or topographic discontinuities acting as favored interaction areas [3]. Patchy particles can form low-dimensional assemblies, such as clusters [4-9], two-dimensional (2D) networks [10] and one-dimensional (1D) chains [11-19]. Indeed, since the pioneer work of Onoe et al. [20], chaining of patchy particles has attracted a lot of attention in the past decade. Murphy and co-workers firstly reported that the density of cetyltrimethylammonium bromide (CTAB) ligands is lower at the tips of gold nanorods making possible to site-specifically bind biotin disulfide and therefore link the NPs end-to-end by adding streptavidin [21]. 
Kumacheva and co-workers enhanced the patchiness of the CTAB-coated gold nanorods by the functionalization of their tips with thiol-terminated polystyrene (PS) chains, which enabled the formation of linear and cyclic colloidal polymers when dispersed in binary solvent mixtures [22-27]. The driving force of the polymerization of the tip-functionalized nanorods derived from the solvation free energy reduction between the isolated particles and their assembly. Pine and co-workers subjected organosilica microspheres bearing one dimple to depletion conditions and observed they assembled in a head-to-tail fashion into polymeric worm-like chains [28]. Similar results were obtained by Tigges and Walther by using cone-shaped microparticles fabricated by direct 3-D laser writing [29]. The same team showed that divalent DNA origami cuboids can self-assemble into 1D fibrils [30]. Monodisperse patchy micelles, prepared by self-assembly of block copolymers, were also extensively used as building units to synthesize colloidal polymers [31-38]. For instance, Gröschel et al. obtained highly regular chains from tri-block copolymers made of polystyrene-block-poly(3-butenyl(dodecyl)sulphane) -block-poly(methyl methacrylate) when the solvent quality was reduced to a critical threshold for the PS segments [32]. Similarly, Sohn and co-workers reported the polymerization of two-patch micelles obtained from PS-poly(4-vinyl-pyridine) diblock copolymers by adding water [34]. The possibility to reach block or random colloidal copolymers was demonstrated using two differently-sized micelles, i.e. with different block lengths or micelles labelled with two types of quantum dots [35]. Lastly, branching was induced in a controlled way by employing three-patch micelles [36].

In this study, we produced colloidal chains polymerized from two-patch silica NPs, which contain PS chains at the bottom of their cavities, by reducing the solvent quality for the latter ones. The kinetics of the colloidal polymerization was analyzed and we found that it followed a two-stage process. Upon the addition of three-patch NPs, we induced chain branching whereas the mixing of preformed homopolymers led to the formation of block copolymers.

\section{Experimental}

\subsection{Chemicals}

Styrene $(99.5 \%$, with c.a. 50 ppm 4-tert-butyl catechol as stabiliser), sodium dodecyl sulfate (SDS, 99\%),
L-arginine $(99 \%)$, sodium persulfate $(\geq 99 \%)$, tetraethoxysilane (TEOS, $299 \%$ ), (3-aminopropyl)triethoxysilane (APTES, 99\%), (3-mercaptopropyl)trimethoxysilane (MPTMS, 95\%), hydroxylamine hydrochloride ( $\left.\mathrm{NH}_{2} \mathrm{OH} . \mathrm{HCl}, 98 \%\right)$, gold chloride hydrate $\left(\mathrm{HAuCl}_{4}, 99.999 \%\right)$, potassium carbonate $\left(\mathrm{K}_{2} \mathrm{CO}_{3}\right)$ and tetrakis(hydroxymethyl)phosphonium chloride solution (THPC, $80 \%$ in water), sodium hydroxide ( $\geq 98.5 \%$, microprills), dimethylformamide (DMF, $\geq 99 \%$ ), and tetrahydrofuran (THF, contains $250 \mathrm{ppm}$ BHT as an inhibitor) were purchased from Sigma-Aldrich. Methacryloxypropyltrimethoxysilane (MPS, 98\%) and methacryloxymethyltrimethoxysilane (MMS, 95\%) were purchased from $\mathrm{ABCR}$, ammonia $(28-30 \%)$ and sodium chloride from JT. Baker, ethanol (99\%) from Atlantic Labo and Synperonic ${ }^{\circledR}$ NP 30 from Fluka. Deionised water with a resistivity of $18.2 \mathrm{M} \Omega . \mathrm{cm}$ at $25^{\circ} \mathrm{C}$ was obtained from a Milli-Q system (Millipore). All chemicals were used without further purification.

\subsection{Synthesis of the multipod-like particles}

We prepared batches of bipods and tripods, consisting of a central silica core surrounded by two or three PS satellite nodules, by seeded-growth emulsion polymerization of styrene, according to a procedure we published previously [39]. We used two batches of $55 \mathrm{~nm}$-silica seeds, previously surface-modified with MPS or MMS, respectively, and a surfactant mixture ( 3 g.L-1 $)$ of Symperonic ${ }^{\circledR}$ NP30 and SDS. The polymerization was performed at $70^{\circ} \mathrm{C}$ for $6 \mathrm{~h}$. The experimental conditions and composition of the batches are described in Table S1 in the Electronic Supplementary Material (ESM).

\subsection{Silica core regrowth}

We regrew the silica cores of the multipods using a method that we reported previously [40]. $1 \mathrm{~mL}$ of the as-obtained silica/PS multipods dispersion was mixed with $45.5 \mathrm{~mL}$ ethanol and $3.2 \mathrm{~mL}$ ammonia in a $100-\mathrm{mL}$ round flask equipped with a magnetic stirrer. To regrow the silica core of the bipods from 55 to $155 \mathrm{~nm}$, we added $1.6 \mathrm{~mL}$ of a TEOS solution (10 vol. \% in ethanol) at the rate of $0.5 \mathrm{~mL} / \mathrm{h}$. To regrow the silica core of the bipods from 55 to $190 \mathrm{~nm}$, an iterative method was used to avoid secondary silica nucleation. The volume of TEOS was added in two shots, e.g. $0.2 \mathrm{~mL}$ and $0.3 \mathrm{~mL}$, separated by an intermediary washing stage of two centrifugation/redispersion cycles in ethanol $(12,000$ g; $10 \mathrm{~min}$ ). To regrow the silica core of the tripods from 55 to $140 \mathrm{~nm}$, we added $1.18 \mathrm{~mL}$ of a TEOS/ethanol mixture (10 vol. \% in ethanol) at the 
rate of $1 \mathrm{~mL} / \mathrm{h}$. One hour after the completion of TEOS addition, the NPs were washed by two centrifugation/redispersion cycles in ethanol $(12,000$ $\mathrm{g} ; 10 \mathrm{~min} ; 25 \mathrm{~mL}$ ). Figure $\mathrm{S} 1$ in the ESM shows that while growing, the silica surface conforms to the shape of the PS nodules.

\subsection{Thiol functionalization of the silica surface}

The surface of the freshly regrown silica core was functionalized by addition of MPTMS at a nominal surface density of 50 molecules $/ \mathrm{nm}^{2}$. The dispersion was aged at room temperature overnight and the functionalized NPs were washed by two centrifugation/redispersion cycles in ethanol $(12,000$ $\mathrm{g}$; $10 \mathrm{~min} ; 25 \mathrm{~mL}$ ).

\subsection{Dissolution of the PS nodules}

For dissolving the PS nodules of the multipods, three centrifugation/redispersion cycles in THF $(12,000 \mathrm{~g}$; $10 \mathrm{~min} ; 20 \mathrm{~mL}$ ) were performed. The final concentration of patchy NPs was adjusted to $3.6 \cdot 10^{14}$ part/L.

\subsection{Chaining of the patchy nanoparticles}

Homopolymers were obtained by adding a calculated volume of a $20 \mathrm{mM} \mathrm{NaCl}$ aqueous solution into a given volume of a two-patch NPs dispersion in THF in order to perform the assembly in a $7 / 3$ (vol/vol) THF/salty water mixture. The mixture was incubated at room temperature under rolling motion. Branched polymers were synthesized in a $7 / 3(\mathrm{v} / \mathrm{v})$ $\mathrm{THF} /$ water mixture by co-assembly of three- and two-patch NPs in a in a feed ratio of $1 / 6$. Block copolymers were prepared by mixing equal volumes of the dispersions of homopolymers, which had been assembled either from $190 \mathrm{~nm}$ and $155 \mathrm{~nm}$ patchy NPs during 4 and 8 hours, respectively, or from bare and thiolated $190 \mathrm{~nm}$ patchy NPs during 4 hours.

In each of all the above cases, after a given incubation time, $40 \mathrm{ml}$ of ethanol were added into the mixture to freeze the chains. The colloidal polymers were recovered by centrifugation $(12,000 \mathrm{~g} ; 10 \mathrm{~min})$ and redispersed in ethanol.

\subsection{Chains decoration by gold nanoparticles}

$2.5 \mathrm{ml}$ of an aqueous dispersion of $\sim 2 \mathrm{~nm}$ gold NPs which were prepared according to a reported protocol [41] were added into $0.5 \mathrm{ml}$ of an ethanolic dispersion of the colloidal block copolymers made of bare and thiol-functionalized patchy NPs after 15 hours of incubation. The mixture was incubated at room temperature under rolling motion for $6 \mathrm{~h}$. The excess of gold nanoparticles was removed by three centrifugation redispersion cycles in water $(5,000 \mathrm{~g}$;
$20 \mathrm{~min} ; 3 \mathrm{~mL})$.

\subsection{Characterization methods}

Transmission electron microscopy (TEM) experiments were performed using a Hitachi H600 microscope operating at an acceleration voltage of 75 $\mathrm{kV}$ and a JEOL JEM 1400 Plus microscope operating at $120 \mathrm{kV}$. We prepared the samples by depositing one drop of the colloidal dispersion on conventional carbon-coated copper grids. We let the liquid evaporate in the open air at room temperature and placed the grids in a box away from dust. Statistics from image analysis were performed over at least 500 multipods or 200 chains. A Tecnai Osiris (Thermo Fisher Scientific) microscope with a field emission gun (FEG), operating at $200 \mathrm{kV}$ and equipped with a Poseidon Select holder, was used for the in situ liquid cell transmission electron microscopy (LC-TEM) experiments. The images were obtained thanks to the BM Ultrascan $2 \mathrm{k} \times 2 \mathrm{k}$ camera with a high sensitivity scintillator (Gatan). Silicon nitride liquid cells were prepared by assembling two microchips $300 \mathrm{~nm}$ apart, each with a $50 \mathrm{~nm}$ thick silicon nitride viewing window. Before assembly, the microchips were immersed in acetone to remove the protective resist coating and cleaned with ethanol. They were then plasma-treated for further cleaning and to improve their surface hydrophilicity. The $\zeta$ potential value of a two-patch silica NPs aqueous dispersion $\left(10^{15} \mathrm{NPs} / \mathrm{L}\right.$, $\mathrm{pH}$ 5.7) was measured using the Malvern Zetasizer 3000 HS setup (Malvern Instruments). The dielectric constant of water was set to 80.4 and the Smoluchowsky constant $\mathrm{f}(\mathrm{ka})$ was 1.5 .

\section{Results and discussion}

3.1 Design of two-patch silica nanoparticles and homopolymers assembly

Figure 1(a) shows the architecture of the two-patch silica NPs that were employed as monomers. They were obtained by the silica core regrowth of silica/PS bipods followed by the selective dissolution of their PS nodules [40]. They exhibit a disk-like morphology with a mean diameter and width of $190 \pm 10$ and $60 \pm 5$ $\mathrm{nm}$, respectively, and thus preferentially lye on one of their sides onto the TEM grid (Fig. 1(b)). 
a)
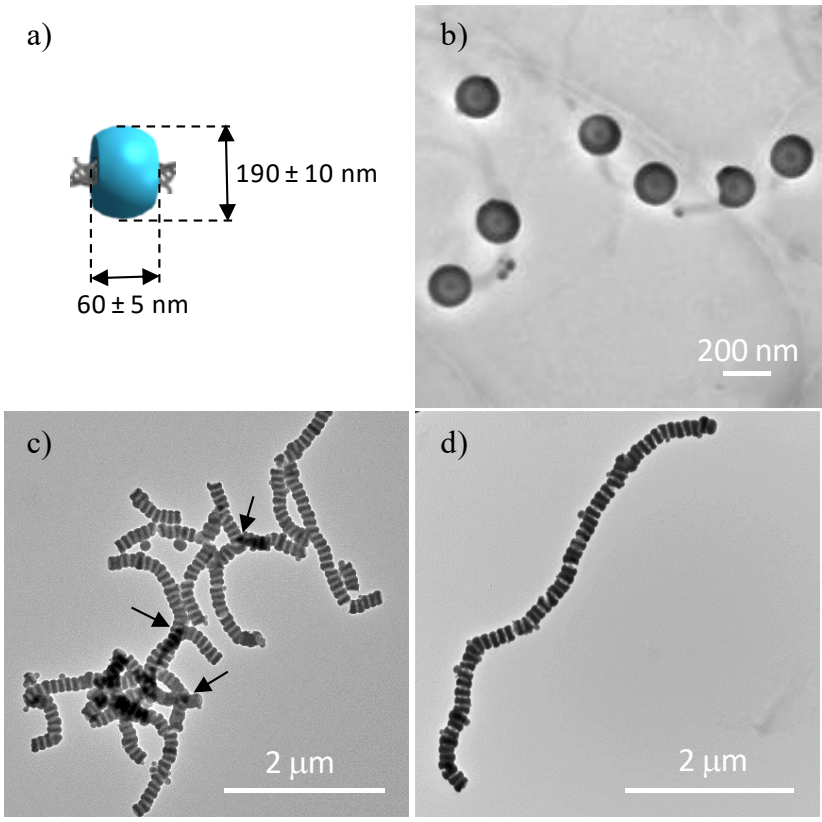

Figure 1 Schematics (a) and TEM image (b) of the two-patch monomers composed of dimpled silica NPs with PS chains grafted at the bottom of their cavities. TEM images of colloidal homopolymers after incubating $3 \mathrm{~mL}$ of the two-patch NPs for 15 hours in to a $7 / 3$ (vol/vol) THF/salty water mixture (c, d).

We have already showed that a few PS chains with number-average mass higher than 500000 gmol-1 $^{-1}$ are covalently grafted onto the initial silica seed surface and remain at the bottom of the two dimples of the patchy NPs after dissolution of the PS nodules [42]. To induce NPs self-assembly, we took benefit of the presence of these PS "residues" that are expected to become sticky in a good/bad solvent mixture. We introduced salty water into the NPs dispersion in THF, thereby reducing both the electrostatic repulsions between NPs due to negatively charged silanolate groups at their surface (the $\zeta$ potential of the patchy NPs was - $42 \mathrm{mV}$ at $\mathrm{pH}$ 5.7) and solvent quality for the PS chains, which thus formed physical bonds between the NPs to minimize the free surface energy of the system [23-24]. As shown in Fig. 1(c), colloidal polymers were successfully synthesized after 15 hours. Some chains grew up to $\sim 6$ microns and contained up to $\sim 60$ monomers, (Fig. 1(d)). Chains composed of $\sim 155 \mathrm{~nm}$ patchy NPs were also produced in a similar way (Fig. S2 in the ESM). In order to verify that the transfer of the chains' dispersion onto the TEM grid did not alter the structure of the colloidal polymers nor favor their formation thanks to possible capillary forces, we performed LC-TEM experiments. Figure 2(a) shows the formation of chains which are similar to those characterized by TEM (Fig. 2(b)), indicating that the grid preparation did not induce any modification of the chains.

\subsection{Kinetics of the polymerization}

We studied the kinetics of the chains formation as a function of the incubation time by statistical analysis of the TEM images recorded at different assembly times (Figs. 2(b) - 2(d)). Fig. 2(e) shows a shift of the distribution of chains with different lengths toward larger values with time, indicating the continuous growth of chains. By analogy with molecular polymerization, we further characterized the chains formation by using the number-average degree of polymerization, $\bar{X}_{n}$, defined as: $\bar{X}_{n}=\frac{\sum n_{x} x}{\sum n_{x}}$, where $x$ is the number of patchy NPs in the chain and $n_{x}$ is the number of chains containing $x$ patchy NPs. The individual NPs were not included in the calculations. Fig. 2(f) shows the evolution of $\bar{X}_{n}$ with time for three different volumes of monomers (ca. $0.5 \mathrm{~mL}, 2$ $\mathrm{mL}$ and $3 \mathrm{~mL}$ ). A linear relationship can be observed at the initial stage $(t<2 \mathrm{~h})$, which is a characteristic of reaction-controlled step-growth polymerization, in which the reactivity of the patches is independent of the chain length [23-24, 43]. According to the relation: $\bar{X}_{n}=2\left[M_{0}\right] k t+1$, where $\left[M_{0}\right], k$ and $t$ are the initial concentration of patchy NPs, the polymerization rate constant and the incubation time, respectively, which is characteristic of the kinetics of the polymerization of bifunctional monomers with identical functional end groups [44], we derived $k$ from the linear fitting of $\bar{X}_{n} \sim t$ curves. We found that $k=7.02 \cdot 10^{5} \mathrm{~L} \cdot \mathrm{mol}^{-1} . \mathrm{s}^{-1}, 1.37 \cdot 10^{6} \mathrm{~L} \cdot \mathrm{mol}^{-1} \cdot \mathrm{s}^{-1}$ and 3.46.106 $\mathrm{L} . \mathrm{mol}^{-1} \cdot \mathrm{s}^{-1}$, for samples prepared with 3, 2, and $0.5 \mathrm{~mL}$ of patchy NPs, respectively. These values are similar to that found for the copolymerization of inorganic NPs [43] and are significantly larger than the value reported for the polymerization of gold nanorods [23]. We presume that the specific shape of the two-patch NPs, which facilitates their mutual orientation, increases the polymerization rate. At the longer time $(t>2 h)$, a nonlinear relationship between $\bar{X}_{n}$ and $t$ started appearing (Fig. 2(f)). The 
polymerization of patchy NPs seems to follow a different pathway, that is, most likely, a "diffusion-controlled" stage, which can be possibly attributed to the fact that the orientation of the chains or their sedimentation becomes the rate-limiting factor when they become relatively long.

Another feature confirming the "diffusion-controlled" polymerization stage consists in the calculation of the polydispersity index, PDI, which is defined as: $P D I=\frac{\bar{X}_{w}}{\bar{X}_{n}}$, where $\bar{X}_{w}=\frac{\sum n_{x} x^{2}}{\sum n_{x} x}$ is the weight-average degree of polymerization. In fact, the PDI was found to be smaller than the value predicted by Flory's model (i.e. $P D I=2-1 / \bar{X}_{n}$ ) when the system was in the "diffusion-controlled" stage. For example, after 4 h assembly, $\bar{X}_{n}=7.2$ when $3 \mathrm{~mL}$ of patchy NPs were used and the PDI was measured to be $\sim 1.70$, which is smaller than the theoretical prediction of 1.86 based on the Flory's model.

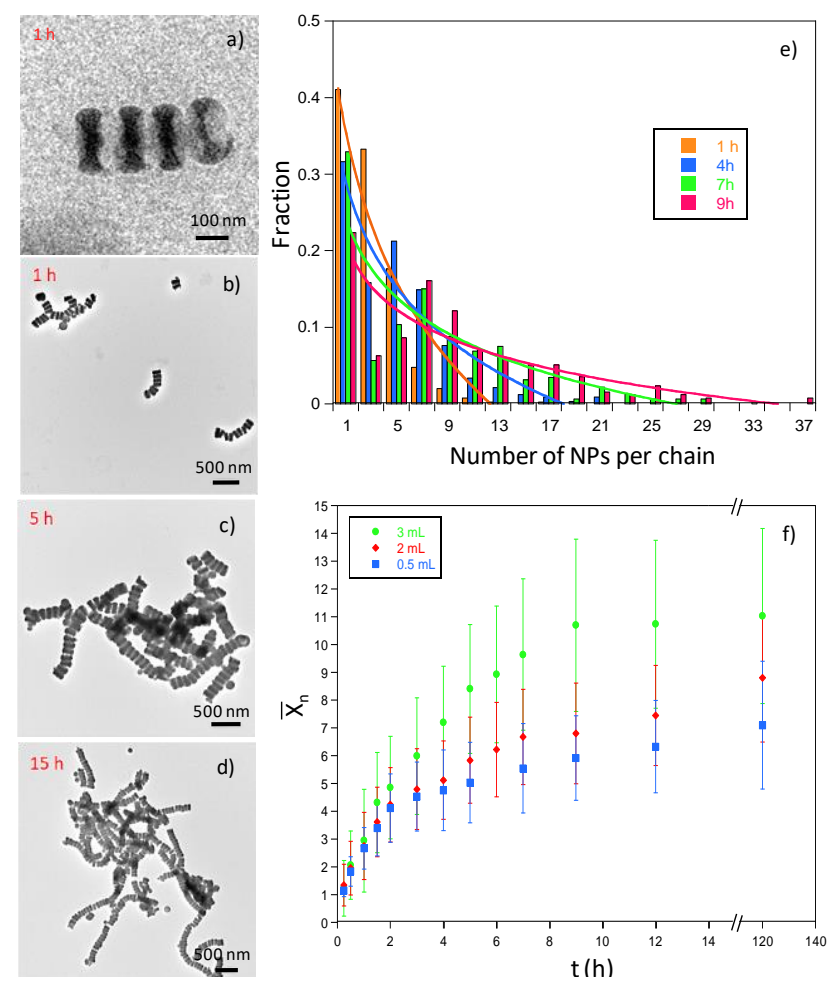

Figure 2 LC-TEM image (a) and TEM images (b) - (d) showing the time-dependent growth of the colloidal polymers. (e) Distribution of the chain length at different assembly times when $3 \mathrm{~mL}$ of two-patch NPs were used. (f) Variation in $\bar{X}_{n}$ with time for different volumes of two-patch NPs.

\subsection{Branched polymers}

The presence of a small fraction $(\sim 2 \%)$ of three-patch NPs as byproducts in the batch of two-patch NPs resulted in the occasional branching of the homopolymers, as marked by the arrows in Fig. 1(c) and clearly shown in Fig 3(a). We thus decided to synthesize a batch of three-patch NPs (Fig. S3 in the ESM) and to use them as branching points on purpose. We mixed these three-patch NPs with two-patch NPs in a feed ratio of $1 / 6$ and branched polymers in which three-patch NPs are connected to 1 (red arrow), 2 (white arrow) or 3 chains (black arrow) were obtained after 15 hours of assembly (Fig. $3(b)-3(d))$. When the feed ratio was increased to $1 / 1$, ramified networks were obtained in which three-patch NPs can be connected to each other (Fig. $\mathrm{S} 4$ in the ESM).
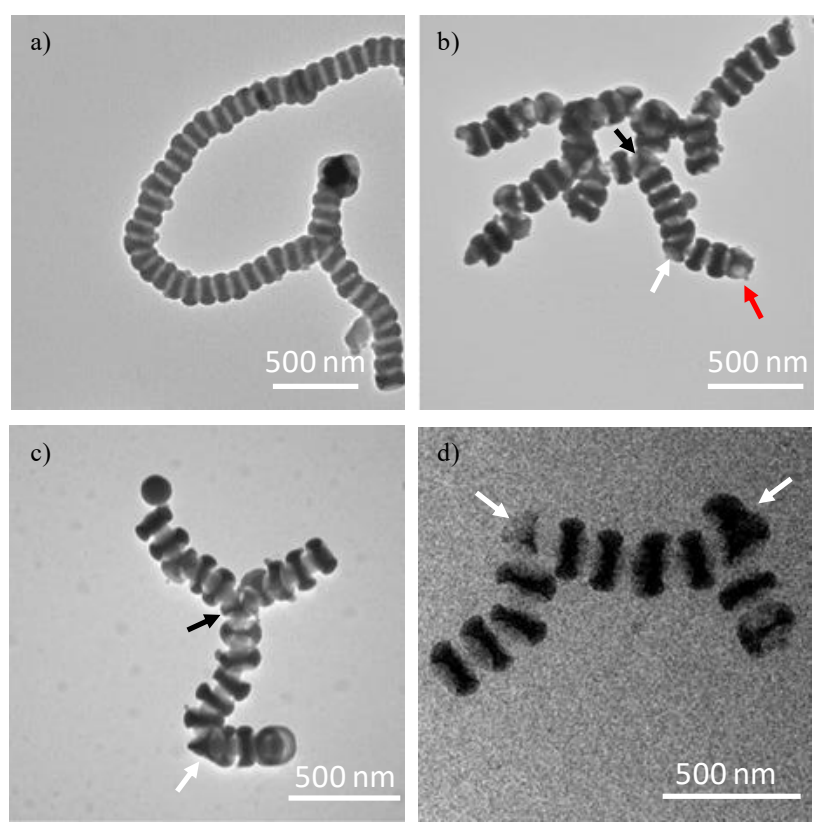

Figure 3 TEM image of chain branching induced by one three-patch byproduct (a). TEM (b, c) and LC-TEM (d) images of branched polymers synthesized by co-assembly of two- and three-patch NPs in a 7/3 ( vol/vol) THF/salty water mixture during 15 hours.

\subsection{Block copolymers}

We further investigated the similarity between polymer synthesis and the self-assembly of two-patch NPs by co-assembling preformed colloidal homopolymers, composed of $190 \mathrm{~nm}$ and $155 \mathrm{~nm}$ patchy NPs. Figures 4(a) - 4(b) show that block copolymers composed of alternating segments of NPs of each size were obtained after 15 hours of incubation. Similarly, the co-assembly of 
homopolymers composed of bare and thiolated 190 $\mathrm{nm}$ patchy NPs was performed. The addition of gold nanoparticles after 15 hours of incubation allowed us to reveal the formation of block copolymers (Fig. $4(\mathrm{c}))$, as they were only grafted onto the thiolated silica surface.
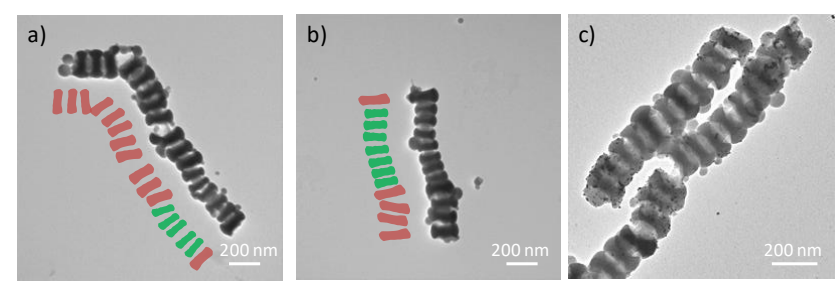

Figure 4 TEM images of copolymers composed of segments of $190 \mathrm{~nm}$ (redrawn in red) and $150 \mathrm{~nm}$ patchy (redrawn in green) NPs (a, b) and of bare and thiolated $190 \mathrm{~nm}$ patchy NPs after addition of gold nanoparticles (c).

\section{Conclusions}

In conclusion, we demonstrate that two-patch silica NPs with PS chains at the bottom of their cavities can be used as monomers to synthesize colloidal homopolymers and block copolymers. The colloidal polymerization process can be quantitatively described by using the classic kinetics of molecular polymerization. We also show that chain networks can be self-assembled through the addition of three-patch NPs, which play the role of branching points. We believe these results can inspire the bottom-up synthesis of a large variety of colloidal polymer architectures with a high degree of control over their structure. Those achieved here are quite good replica of carbyne, also known as the linear acetylenic carbon $-(\mathrm{C} \equiv \mathrm{C})_{\mathrm{n}}$ - and often assimilated to the polycumulene $=(C=C)_{n}=$. In this context, the two-patch NPs imitate sp-hybridized C atoms. But we could expect to prepare more complex polymers as the colloidal analogue of polyethylene $-\left(\mathrm{CH}_{2}-\mathrm{CH}_{2}\right)_{n-}$ could be polymerized from four-patch and one-patch NPs mimicking $\mathrm{sp}^{3}$-hybridized carbon and hydrogen atoms, respectively. Furthermore, we plan in the close future to visualize in situ the colloidal chains by liquid phase transmission electron microscopy in order to determine if they are flexible in solution as presumably because of the length of the PS macromolecules acting as linkers. Such flexibility associated with our capability to selectively functionalize the radial surface of the two-patch silica NPs should allow the colloidal chains to spontaneously fold into 3D structures and may serve as a model for the study of the folding behavior of biopolymers [45].

\section{Acknowledgements}

This work was supported by the Agence Nationale de la Recherche (ENLARgER project, ANR-15-CE09-0010), the LabEx AMADEus (ANR-10-LABX-42) and IdEx Bordeaux (ANR-10-IDEX-03-02), that is, the Investissements $\mathrm{d}$ 'Avenir programme of the French government managed by the Agence Nationale de la Recherche. $\mathrm{W}$. Li and B. Liu are supported by a grant from the China Scholarship Council. Some of the TEM experiments were performed at the Plateforme de Caractérisation des Matériaux (UMS 3626, Pessac, France). A. Arnould, R. Soulas and S. Aguy are greatly thanked for their help during the liquid cell electron microscopy experiments.

Electronic Supplementary Material: Supplementary material (experimental synthesis conditions of the patchy NPs, TEM images of bipods and tripods after silica core regrowth, of chains of $155 \mathrm{~nm}$ NPs and of silica NPs with three cavities) is available in the online version of this article at http://dx.doi.org/10.1007/s12274-***_****_* (automatically inserted by the publisher).

\section{References}

[1] Cademartiri, L.; Bishop, K. J. M. Programmable self-assembly. Nature Mater. 2015, 14, 2-9.

[2] Ravaine, S.; Duguet, E. Synthesis and assembly of patchy particles: recent progress and future prospects. Curr Opin Colloid Interface Sci. 2017, 30, 45-53.

[3] Zhang, L.; Glotzer, S. C. Self-Assembly of patchy particles. Nano Lett. 2004, 4, 1407-1413.

[4] Wang, Y.; Wang, Y.; Breed, D. R.; Manoharan, V. N.; Feng, L.; Hollingsworth, A. D.; Weck, M.; Pine, D. J. Colloids with valence and specific directional bonding. Nature 2012, 490, 51-55.

[5] Sacanna, S.; Irvine, W. T.; M., Chaikin, P. M.; Pine, D. J. Lock and key colloids. Nature 2010, 464, 575-578.

[6] Wang, Y.; Wang, Y.; Zheng, X.; Yi, G.-R.; Sacanna, S.; Pine, D. J.; Weck, M. Three-dimensional lock and key colloids. J. Am. Chem. Soc. 2014, 136, 6866-6869.

[7] Rouet, P.-E.; Chomette, C.; Duguet, E.; Ravaine, S. Colloidal molecules from valence-endowed nanoparticles by covalent chemistry. Angew. Chemie Int. Ed. 2018, 57, 15754-15757.

[8] Rouet, P.-E., Chomette, C.; Adumeau, L.; Duguet, E.; Ravaine, S. Colloidal chemistry with patchy silica nanoparticles. Beilstein $J$. Nanotechnol. 2018, 9, 2989-2998.

[9] Li, W.; Ravaine, S.; Duguet, E. Clustering of asymmetric dumbbell-shaped silica/polystyrene nanoparticles by solvent-induced self-assembly. J. Colloid Interface Sci. 2020, 560, 639-648. 
[10] Chen, Q.; Bae, S. C.; Granick, S. Directed self-assembly of a colloidal kagome lattice. Nature 2011, 469, 381-384.

[11] Lunn, D. J.; Finnegan, J. R.; Manners, I. Self-assembly of "patchy" nanoparticles: a versatile approach to functional hierarchical materials. Chem. Sci. 2015, 6, 3663-3673.

[12] Song, P.; Wang, Y.; Wang, Y.; Hollingsworth, A. D.; Weck, M.; Pine, D. J.; Ward, M. D. Patchy particle packing under electric fields. J. Am. Chem. Soc. 2015, 137, 3069-3075.

[13] Yan, J.; Han, M.; Zhang, J.; Xu, C.; Luijten, E.; Granick S. Reconfiguring active particles by electrostatic imbalance. Nature Mater. 2016, 15, 1095-1099.

[14] Hill, L. J.; Pyun, J. Colloidal polymers via dipolar assembly of magnetic nanoparticle monomers. ACS Appl. Mater. Interfaces 2014, 6, 6022-6032.

[15] Shaw, S.; Cademartiri, L. Nanowires and nanostructures that grow like polymer molecules. Adv. Mater. 2013, 25, 4829-4844.

[16] Liu, K.; Zhao, N.; Kumacheva, E. Self-assembly of inorganic nanorods. Chem. Soc. Rev. 2011, 40, 656-671.

[17] Luo, B.; Smith, J. W.; Wu, Z.; Kim, J.; Ou, Z.; Chen, Q. Polymerization-like co-assembly of silver nanoplates and patchy spheres. ACS Nano 2017, 11, 7626-7633.

[18] Onishi, S.; Tokuda, M.; Suzuki, T.; Minami, H.. Preparation of Janus particles with different stabilizers and formation of one-dimensional particle arrays. Langmuir 2015, 31, 674-678.

[19] Zhao, S.; Wu, Y.; Lu, W.; Liu, B. Capillary force driving directional 1D assembly of patchy colloidal discs. ACS Macro Letters 2019, 8, 363-367.

[20] Onoe, H.; Matsumoto, K.; Shimoyama, I. Three-dimensional sequential self-assembly of microscale objects. Small 2007, 3, 1383-1389.

[21] Caswell, K. K.; Wilson, J. N.; Bunz, U. H. F.; Murphy, C. J. Preferential end-to-end assembly of gold nanorods by biotin-streptavidin connectors. J. Am. Chem. Soc. 2003, 125, 13914-13915.

[22] Nie, Z.; Fava, D.; Kumacheva, E.; Zou, S.; Walker, G. C.; Rubinstein, M. Self-assembly of metal-polymer analogues of amphiphilic triblock copolymers. Nature Mater. 2007, 6, 609-614.

[23] Liu, K.; Nie, Z.; Zhao, N.; Li, W.; Rubinstein, M.; Kumacheva, E. Step-growth polymerization of inorganic nanoparticles. Science 2010, 329, 197-200.

[24] Choueiri, R. M.; Galati, E.; Klinkova, A.; Thérien-Aubin, H.; Kumacheva, E. Linear assembly of patchy and non-patchy nanoparticles. Faraday Discuss. 2016, 191, 198-204.

[25] Klinkova, A.; Therien-Aubin, H.; Choueiri, R. M.; Rubinstein, M.; Kumacheva, E. Colloidal analogs of molecular chain stoppers. Proc. Natl. Acad. Sci. 2013, 110, 18775-18779.

[26] Nie, Z.; Fava, D.; Rubinstein, M.; Kumacheva, E. "Supramolecular" assembly of gold nanorods end-terminated with polymer "pom-poms": effect of pom-pom structure on the association modes. J. Am. Chem. Soc. 2008, 130, 3683-3689.

[27] Liu, K.; Resetco, C.; Kumacheva, E. Salt-mediated kinetics of the self-assembly of gold nanorods end-tethered with polymer ligands. Nanoscale 2012, 4, 6574-6580.

[28] Sacanna, S.; Irvine, W. T. M.; Chaikin, P. M.; Pine, D. J. Lock and key colloids. Nature 2010, 464, 575-578.
[29] Tigges, T.; Walther, A. Hierarchical self-assembly of 3D-printed lock-and-key colloids through shape recognition. Angew. Chemie Int. Ed. 2016, 55, 11261-11265.

[30] Tigges, T.; Heuser, T.; Tiwari, R.; Walther, A. 3D DNA origami cuboids as monodisperse patchy nanoparticles for switchable hierarchical self-assembly. Nano Lett. 2016, 16, 7870-7874.

[31] Gröschel, A. H.; Schacher, F. H.; Schmalz, H.; Borisov, O. V.; Zhulina, E. B.; Walther, A.; Müller, A. H. E. Precise hierarchical self-assembly of multicompartment micelles. Nat. Commun. 2012, 3,710 .

[32] Gröschel, A. H.; Walther, A.; Löbling, T. I.; Schacher, F. H.; Schmalz, H.; Müller, A. H. E. Guided hierarchical co-assembly of soft patchy nanoparticles. Nature 2013, 503, 247-251.

[33] Löbling, T. I.; Borisov, O.; Haataja, J. S.; Ikkala, O.; Gröschel, A. H.; Müller, A. H. E. Rational design of ABC triblock terpolymer solution nanostructures with controlled patch morphology. Nature Commun. 2016, 7, 12097.

[34] Kim, J.-H.; Kwon, W. J.; Sohn, B.-H. Supracolloidal polymer chains of diblock copolymer micelles. Chem. Commun. 2015, 51, 3324-3327.

[35] Kim, K.; Jang, S.; Jeon, J.; Kang, D.; Sohn, B. H. Fluorescent supracolloidal chains of patchy micelles of diblock copolymers functionalized with fluorophores. Langmuir 2018, 34, 4634-4639.

[36] Lee, S.; Jang, S.; Kim, K.; Jeon, J.; Kim, S. S.; Sohn, B. H. Branched and crosslinked supracolloidal chains with diblock copolymer micelles having three well-defined patches. Chem. Commun. 2016, 52, 9430-9433.

[37] Jang, S.; Kim, K.; Jeon, J.; Kang, D.; Sohn, B. H. Supracolloidal chains of patchy micelles of diblock copolymers with in situ synthesized nanoparticles. Soft Matter 2017, 13, 6756-6760.

[38] Qiu, H.; Hudson, Z. M.; Winnik, M. A.; Manners, I. Multidimensional hierarchical self-assembly of amphiphilic cylindrical block comicelles. Science 2015, 347, 1329-1332.

[39] Désert, A.; Morele, J.; Taveau, J.-C.; Lambert, O.; Lansalot, M.; Bourgeat-Lami, E.; Thill, A.; Spalla, O.; Belloni, L.; Ravaine, S.; Duguet, E. Nanoscale 2016, 8, 5454-5469.

[40] Désert, A.; Hubert, C.; Fu, Z.; Moulet, L.; Majimel, J.; Barboteau, P.; Thill, A.; Lansalot, M.; Bourgeat-Lami, E.; Duguet, E.; Ravaine S. Angew. Chem. Int. Ed. 2013, 52, 11068-11072.

[41] Duff, D. G.; Baiker, A.; Edwards, P. P. J. Chem. Soc., Chem. Commun. 1993, 96-98.

[42] Chomette, C.; Duguet, E.; Mornet, S.; Yammine, E.; Manoharan, V. N.; Schade, N. B.; Hubert, C.; Ravaine, S.; Perro, A.; Treguer-Delapierre, M. Faraday Discuss. 2016, 191, 105-116.

[43] Yi, C.; Yang, Y.; Nie, Z. Alternating copolymerization of inorganic nanoparticles. J. Am. Chem. Soc. 2019, 141, 7917-7925.

[44] Flory, P. Principles of polymer chemistry; Cornell University Press Ed., 1953.

[45] Coluzza, I.; van Oostrum, P. D. J.; Capone, B.; Reimhult, E.; Dellago, C. Design and folding of colloidal patchy polymers. Soft Matter 2013, 9, 938-944. 



\section{Electronic Supplementary Material}

\section{Self-assembly of colloidal polymers from two-patch silica nanoparticles}

Weiya $\mathrm{Li}^{1,2}$, Bin Liu ${ }^{1,2}$, Céline Hubert ${ }^{1,3}$, Adeline Perro ${ }^{3}$, Etienne Duguet ${ }^{2}$, and Serge Ravaine ${ }^{1}(\varangle)$

${ }^{1}$ Univ. Bordeaux, CNRS, CRPP, UMR 5031, F-33600 Pessac, France

${ }^{2}$ Univ. Bordeaux, CNRS, ICMCB, UMR 5026, F-33600 Pessac, France

${ }^{3}$ Univ. Bordeaux, CNRS, Bordeaux INP, ISM, UMR 5255, F-33400 Talence, France

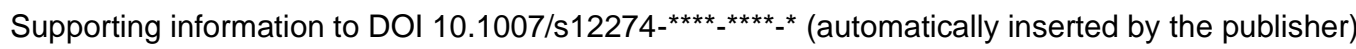

Table S1 Experimental conditions and final compositions of the seeded-growth emulsion polymerization of styrene.

\begin{tabular}{lcc} 
& Bipod batch & Tripod batch \\
\hline $\mathrm{D}_{\text {silica }}(\mathrm{nm})$ & 55 & 55 \\
$\mathrm{~N}_{\text {silica }}\left(10^{15} \mathrm{~L}^{-1}\right)$ & 18 & 18 \\
[styrene $]_{0}\left(\right.$ mol. $\left.\mathrm{L}^{-1}\right)$ & 0.96 & 0.96 \\
Coupling agent & $\mathrm{MPS}$ & $\mathrm{MMS}$ \\
(nominal amount) & $\left(0.35 \mathrm{fct} / \mathrm{nm}^{2}\right)$ & $\left(0.35 \mathrm{fct} / \mathrm{nm}^{2}\right)$ \\
NP30/ SDS (\%/\%) & $99 / 1$ & $98 / 2$ \\
\hline \% bipods & & \\
\% tripods & 97 & 6 \\
\% tetrapods & 2 & 75 \\
\% others & $<1$ & 9 \\
& $<1$ & 10 \\
\hline
\end{tabular}


a)

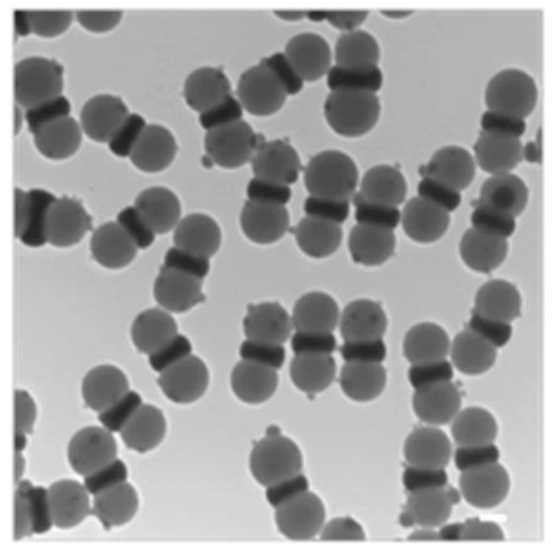

b)

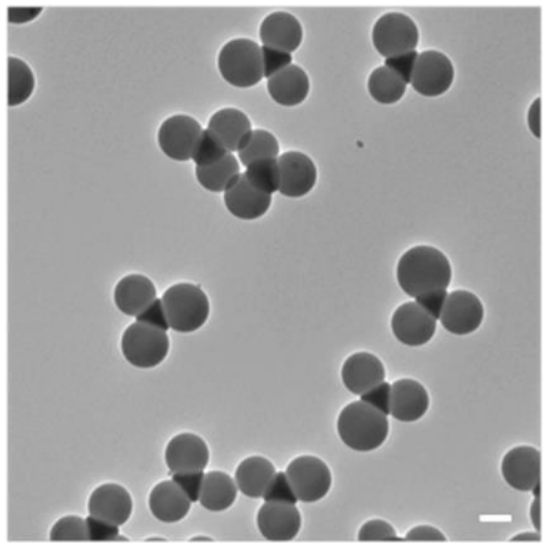

Figure S1 TEM images of the bipods (a) and the tripods (b) after the silica core regrowth. Scale bars: $100 \mathrm{~nm}$.

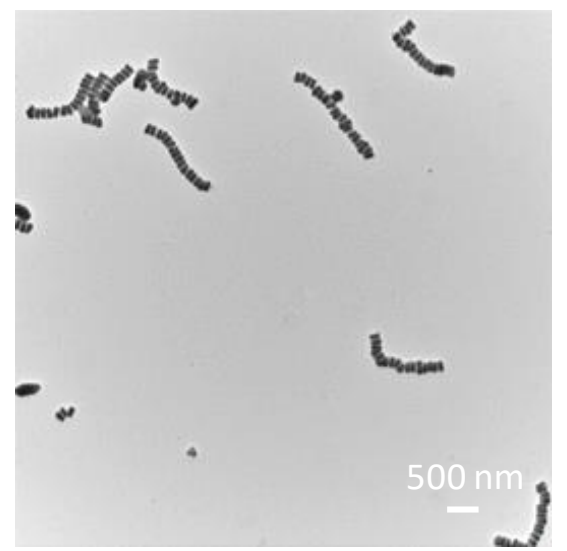

Figure S2 TEM image of colloidal polymers made of $155 \mathrm{~nm}$-patchy NPs after 19 hours assembly. 
a)

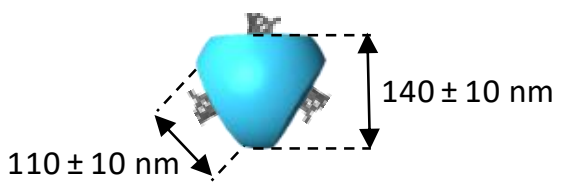

b)

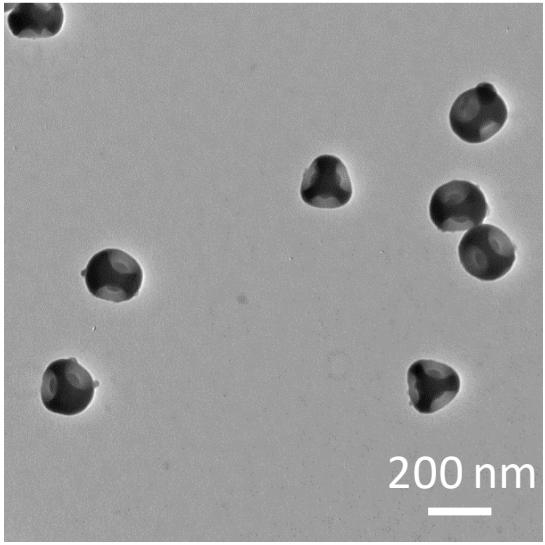

Figure S3 Schematics (a) and TEM image (b) of the three-patch monomers.

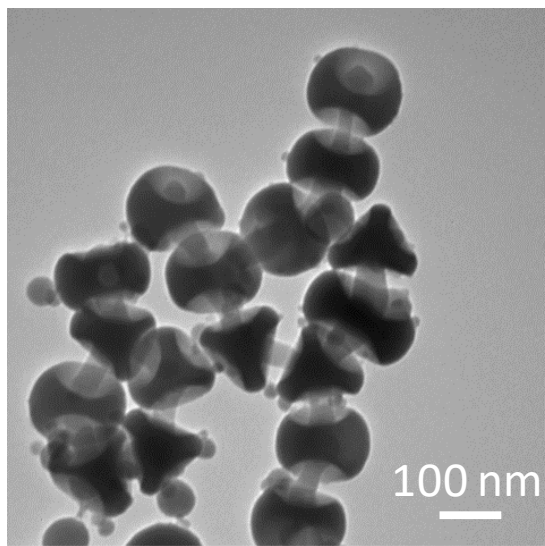

Figure S4 TEM image of branched networks synthesized by co-assembly of two- and three-patch NPs (1/1 ratio) in a 7/3 (vol/vol) THF/salty water mixture during 15 hours.

Address correspondence to Prof S. Ravaine: serge.ravaine@crpp.cnrs.fr 